\title{
Chromatin organization and timing of polar body I extrusion identify developmentally competent mouse oocytes
}

\author{
FEDERICA CAVALERA ${ }^{1,2}$, MARIO ZANONI ${ }^{1,2}$, VALERIA MERICO ${ }^{1,2}$, LUCIA SACCHI $^{2,3}$, RICCARDO BELLAZZI $^{2,3}$, \\ SILVIA GARAGNA*,1,2 and MAURIZIO ZUCCOTTI ${ }^{*, 1,2}$ \\ ${ }^{1}$ Laboratorio di Biologia dello Sviluppo, Dipartimento di Biologia e Biotecnologie "Lazzaro Spallanzani", ${ }^{2}$ Centre for Health \\ Technologies (C.H.T.) and ${ }^{3}$ Dipartimento di Ingegneria Industriale e dell'Informazione, University of Pavia, Pavia, Italy
}

\begin{abstract}
In the mouse, the use of the DNA-binding fluorochrome Hoechst 33342 allows the classification of fully-grown antral oocytes into two categories distinguished by their chromatin conformation: surrounding nucleolus (SN) and not-surrounding nucleolus (NSN) oocytes, the former capable of completing development, the latter unable to proceed beyond the 2-cell stage. In the present study, time-lapse observation of SN and NSN oocyte GV-to-MII transition highlighted differences in the timing of germinal vesicle breakdown (GVBD) and polar body I (PB-I) extrusion. PB-I extrusion, but not GVBD, revealed the presence of three main groups of significantly different oocytes: Group A (456-576 min) comprising mainly SN oocytes (91.4\%), group B (584-728 min) entailing an almost equivalent percentage of SN (52.7\%) and NSN (47.3\%) oocytes, whereas group C (736-896 $\mathrm{min})$ consisting of almost all NSN (94.4\%) oocytes. In a further set of time-lapse experiments, GV oocytes were in vitro matured without Hoechst staining and, depending on the timing of PB-I extrusion, sorted into group A, B or C, inseminated with sperm and observed throughout preimplantation. The results show that $26.2 \pm 12.3 \%$ of group $A, 2.4 \pm 5.0 \%$ of group $B$ and none of group C MII oocytes developed to blastocyst. Overall, this study shows that SN oocytes that complete MI earlier are those with a better developmental competence. The possibility to avoid the use of the invasive DNA-binding fluorochrome Hoechst is relevant for future applications in human and domestic animal reproductive technologies.
\end{abstract}

KEY WORDS: oocyte, chromatin organization, in vitro maturation, polar body I, preimplantation development

\section{Introduction}

When stained with the fluorochrome Hoechst 33342, fully-grown antral oocytes display two main types of chromatin organization: an oocyte type shows an Hoechst-positive heterochromatic ring surrounding the nucleolus and for this reason it is named SurroundedNucleolus (SN); the other type lacks of this ring and it is called Not Surrounded-Nucleolus (NSN) oocyte. Chromatin organization is just a gross marker behind which lays a number of molecular, cytological and functional differences (Zuccotti et al., 2005; Tan et al., 2009; Zuccotti et al., 2011): i) SN oocytes are transcriptionally silent whereas NSN are active (Debey et al., 1993; Bouniol-Baly et al., 1999); ii) the levels of histone acetylation and methylation as well as DNA methylation are higher in SN compared to NSN oocytes (Kageyama et al., 2007); iii) microtubule organizing centers form around SN oocytes nucleoli, but not around those of NSN oocytes (Wickramasinghe and Albertini, 1992; Can et al., 2003); iv) vacuolization is a feature within NSN nucleoli (Debey et al., 1993).

However, the most remarkable difference between the two types of oocytes is their developmental competence. Whilst both mature in vitro to metaphase II (MII) and after fertilization reach the 2-cell stage, only those with an SN-type of chromatin organization may complete preimplantation development (Zuccotti et al., 1995; 1998; 2002) and, after in utero transfer, reach full-term development (Inoue et al., 2008). On the contrary, NSN oocytes arrest development at

\footnotetext{
Abbreviations used in this paper: GVBD, germinal vesicle breakdown; IVM, in vitro maturation; MII, metaphase II; NSN, not-surrounding nucleolus; PB-I, polar body I; SN, surrounding nucleolus.
}

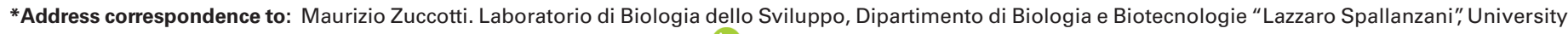
of Pavia, Via Ferrata, 9, 27100 Pavia. e-mail: maurizio.zuccotti@unipv.it - iD https://orcid.org/0000-0003-4648-0663

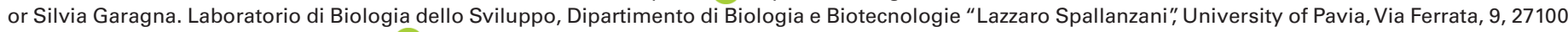
Pavia. E-mail: silvia.garagna@unipv.it - iD https://orcid.org/0000-0003-0803-2405
} 
the 2-cell stage, i.e., at the time of embryonic genome activation. Downregulation of maternal effect factors such as Stella and Oct4, required at the maternal-to-embryo transition, and the upregulation of genes implicated in the activation of mitochondrial dysfunction and apoptosis (Zuccotti et al., 2008; 2009; 2012) explain the 2-cell block observed in NSN oocytes.

Altogether, these data indicate a molecular signature of the developmental potential of oocytes with an SN chromatin organization. Nevertheless, the use of an invasive marker like the fluorochrome Hoechst is not, for obvious reasons, the ideal method of oocytes selection when thinking at a possible clinical translation, either in domestic animals or humans. Clearly, finding a non-invasive procedure of classification that could be associated to the SN- or NSN-type of chromatin organization would facilitate future applications. In an earlier study, we suggested a correlation between the timing of germinal vesicle breakdown (GVBD), the polar body I (PB-I) extrusion during in vitro maturation (IVM) and the oocytes chromatin conformation (Belli et al., 2014).

In the present study, using time-lapse observation, we addressed the question of whether these two non-invasive cytological markers could replace the use of Hoechst to select between developmentally competent or incompetent mouse antral oocytes.

\section{Results}

Timing of GVBD and PB-I extrusion during the GV-to-MII transition of SN or NSN oocytes

To pinpoint the occurrence of the GVBD and PB-I extrusion, the IVM of a total of 94 SN and 49 NSN fully-grown antral GV oocytes was observed during $15 \mathrm{hr}$ of time-lapse recording. A typical experiment, repeated 6 times, comprised the isolation of GV oocytes from the ovaries of two females.

Both GVBD and PB-I extrusion occurred significantly earlier in $\mathrm{SN}$ compared to NSN oocytes $(p<0.001)$. When the data of GVBD or PB-I extrusion were analyzed using unsupervised hierarchical clustering, whilst GVBD did not emerge as a discriminating parameter, PB-I extrusion instead highlighted the presence of three significantly ( $p<0.001)$ different groups of oocytes (clusters) (Fig. 1). Group $A$, the most abundant, encompassed all those oocytes that completed MI during a time-interval comprised between 456$576 \mathrm{~min}$ of maturation. Importantly, the great majority $(91.43 \%$; $\mathrm{n}=64)$ of these gametes was of the SN type and only $8.57 \%(n=6)$ displayed an NSN chromatin organization. Group B included a similar percentage of SN (52.73\%; $n=29)$ and NSN (47.27\%; $n=26)$ oocytes that accomplished PB-I extrusion during a time-interval comprised between 584-728 min. Finally, group C attained MI after 736-896 min of IVM and consisted of a majority of NSN (94.44\%; $\mathrm{n}=17)$ and only a single SN (5.56\%) oocyte.

\section{Timing of GVBD and PB-I extrusion during the GV-to-MII tran-} sition of unclassified oocytes

In a further set of time-lapse experiments, PB-I extrusion timeintervals were used as sorting parameter to classify oocytes into group A (456-576 min), B (584-728 min) or C (736-896 min). A total of 9 independent experiments were carried out. In a typical experiment, the ovaries of two females were punctured to isolate an average of $26.8 \pm 7.8$ fully-grown antral GV oocytes. Out of a total of 240 in vitro matured unclassified GV oocytes, $233(97.08 \%)$ reached the MII phase, and of these, 124 (53.21\%) were attrib-

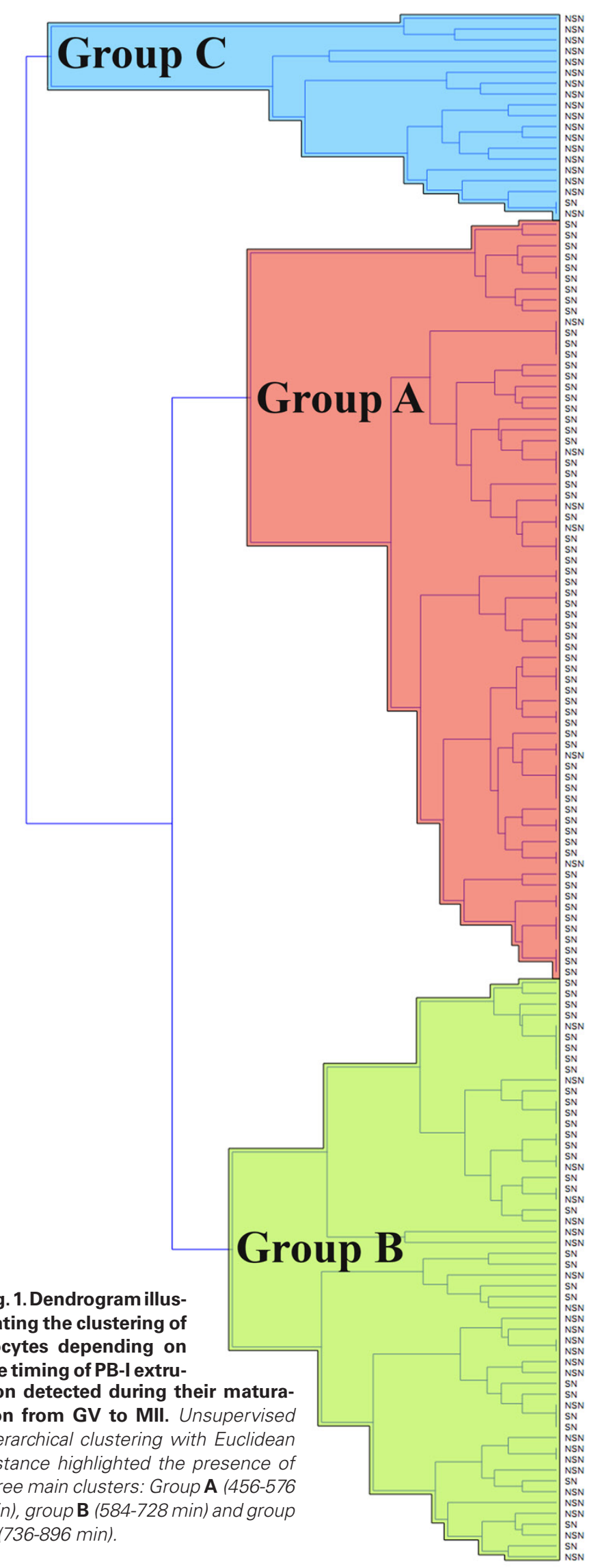


uted to group A, 93 (39.91\%) to group B and 16 $(6.86 \%)$ to group C (Table 1$)$.

\section{Preimplantation development}

Fifthteen hours after the beginning of IVM, Group A, B or C MII oocytes were inseminated with capacitated sperm. Oocytes belonging to group Areached the 2-cell stage with a frequency $(69.0 \pm 20.6 \%)$ similar $(p>0.05)$ to that of group B $(44.9 \pm 15.6 \%)$, but higher $(p=0.005)$ compared to that of group $\mathrm{C}(25.9 \pm 43.4 \%)$ (Table 1$)$. Progression of development to the 4-cell occurred better for group $A(65.2 \pm 12.3 \%)$ compared to group $\mathrm{B}(28.2 \pm 26.1 \%)(p<0.001)$ or group $\mathrm{C}$ $(4.4 \pm 13.3 \%)(p<0.001)$. The morula stage was reached by $42.7 \pm 13.1 \%$ of group A compared to $4.2 \pm 6.8 \%$ group B embryos $(p<0.001)$, but all embryos of group $\mathrm{C}$ arrested at the 4-cell stage. Only group $\mathrm{A}(26.2 \pm 12.3 \%)$ and, much less, group $\mathrm{B}(2.4 \pm 5.0 \%)(p<0.001)$ embryos completed preimplantation development attaining the blastocyst stage. Importantly, group A oocytes completed preimplantation with a frequency of blastocysts $(26.2 \%)$, similar $(p=0.402)$ to that $(28.9 \%)$ obtained with oocytes matured within intact COCs (Table 1).

\section{Polar body I (PB-I) size}

The PB-I size in area is a parameter that correlates with the MII oocyte developmental competence (Rienzi et al., 2008; Navarro et al., 2009; Yi et al., 2013; Almonacid et al., 2018). Compared to control ovulated MII oocytes $\left(403.0 \pm 192.0 \mu \mathrm{m}^{2}\right)$, MII of group A displayed the same PB-I area $\left(344.3 \pm 155.3 \mu \mathrm{m}^{2}\right)(p>0.05)$, whereas both group $B\left(538.74 \pm 195.35 \mu \mathrm{m}^{2}\right)$ and group $C(638.2$ $\left.\pm 354.0 \mu \mathrm{m}^{2}\right)$ PB-Is presented a significantly much larger area $(p<$ 0.001 ) (Fig. 2).

\section{Fertilization capability of groupA, B and Cmetaphase Il oocytes}

Group A, B or C MII oocytes were inseminated with capacitated sperm and, $6 \mathrm{hr}$ later, fixed, stained with DAPI and analyzed for the presence of pronuclei. Fig. 3 shows a representative example of unfertilized (1 pronucleus), monospermic (2 pronuclei) and plurispermic (3 pronuclei) oocytes. The frequency of gametes with 2
A

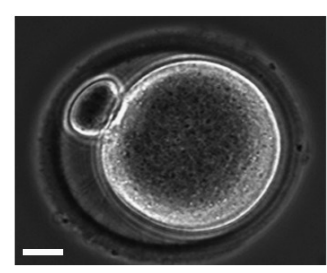

B

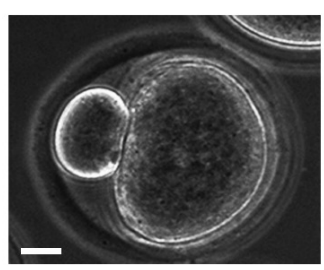

Fig. 2. Polar body-1 (PB-I) area of metaphasell oocytes belonging to groups A, B, C or ovulated. Horizontal bars represent the $95 \%$ confidence intervals for the differences between eans according to the Least Significant Difference statistical test. (A, B) Representative images of an MIl oocyte with a regular- or irregular-size PB-I, respectively. Bar, $20 \mu \mathrm{m}$.

pronuclei was not significantly different $(p>0.05)$ comparing group $A(80.2 \pm 12.2 \%)$, group $B(73.7 \pm 4.0 \%)$ and group $C(73.1 \pm 5.8 \%)$ (Table 2). Similarly, the frequency of unfertilized or plurispermic oocytes was the same ( $p>0.05)$ for group $A(11.2 \pm 13.6 \% ; 11.4$ $\pm 10.8 \%)$, group B $(18.7 \pm 9.4 \% ; 5.6 \pm 7.3 \%)$ and group C $(14.8$ $\pm 17.0 \% ; 15.7 \pm 13.7 \%)$.

\section{Blastocyst quality}

All blastocysts that developed from group $A$ and control, in vivo ovulated, MII oocytes were analyzed by immunolocalization of OCT4 and CDX2 proteins, expressed by the inner cell mass (ICM) and trophectoderm (TE) cells and markers of blastocyst quality (Van Thuan et al., 2006; Mallol et al., 2013). The total number of blastomeres (DAPI) (group A: $30.8 \pm 14.6$; control: $30.0 \pm 8.9 \%$ ), the fraction of ICM (OCT4) (group A: $29.8 \pm 6.3 \%$; control: $26.4 \pm$ $8.0 \%$ ) and TE (CDX2) (group A: $70.0 \pm 6.2 \%$; control: $73.6 \pm 8.0 \%$ ) cells was not significantly different in the two compared groups ( $p>0.05$ ) (Fig. 4).

TABLE 1

PREIMPLANTATION DEVELOPMENTAL COMPETENCE OF METAPHASEII OOCYTES BELONGING TO GROUPS A, B OR C

\begin{tabular}{|c|c|c|c|c|c|}
\hline \multirow{3}{*}{ Stage } & \multicolumn{5}{|c|}{ Mean Percentage \pm S.D. (Number) } \\
\hline & \multicolumn{3}{|c|}{ Cumulus oocyte complexes } & \multirow[t]{2}{*}{ Cumulus oocyte complexes } & \multirow[t]{2}{*}{ Ovulated MII } \\
\hline & $\begin{array}{c}\text { GROUP A } \\
\text { (456-576 min) }\end{array}$ & $\begin{array}{c}\text { GROUP B } \\
\text { (584-728 min) }\end{array}$ & $\begin{array}{c}\text { GROUP C } \\
\text { (736-896 min) }\end{array}$ & & \\
\hline MII & (124) & (93) & (16) & $(102)$ & (64) \\
\hline 2-cell & $69.0 \pm 20.6(81)^{\mathrm{a}}$ & $44.9 \pm 15.6(47)$ & $25.9 \pm 43.4(8)^{\mathrm{a}}$ & $64.7 \pm 13.7(66)$ & $86.9 \pm 13.9(54)$ \\
\hline 4-cell .. & $65.2 \pm 12.3(52)^{\mathrm{a}, \mathrm{b}}$ & $28.2 \pm 26.1(16)^{\mathrm{a}}$ & $4.4 \pm 13.3(2)^{b}$ & $51.6 \pm 12.6(31)$ & $89.8 \pm 9.2(49)$ \\
\hline Morula" & $42.7 \pm 13.1(33)^{c}$ & $4.2 \pm 6.8(3)^{\mathrm{c}}$ & none & $30.5 \pm 5.2(21)$ & $77.8 \pm 15.3(42)$ \\
\hline Blastocyst & $26.2 \pm 12.3(20)^{d}$ & $2.4 \pm 5.0(2)^{d}$ & none & $28.9 \pm 7.8(19)$ & $37.5 \pm 20.6(24)$ \\
\hline
\end{tabular}

Groups A, B and C were compared using the ANOVA test. In the same raw, common superscript letters indicate a significant difference: $a: p=0.005$; b-d: $p<0.001$.

${ }^{\star}$ The developmental rate was calculated based on the number of MII oocytes. ${ }^{\star \star} T$ The developmental rate was calculated based on the number of 2-cell embryos. 
1PN

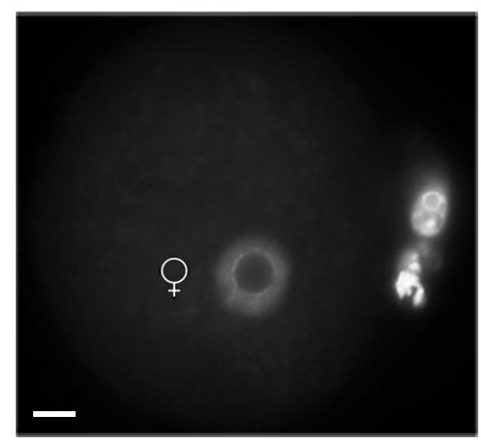

2PNs

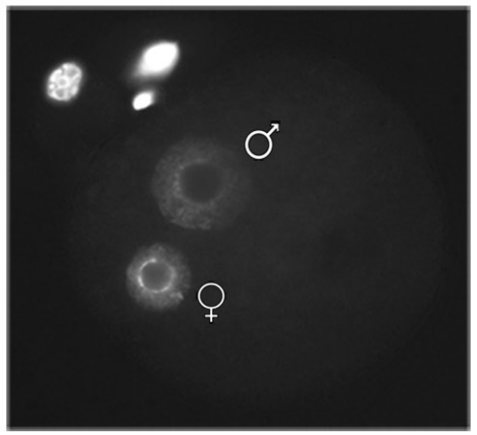

3PNs

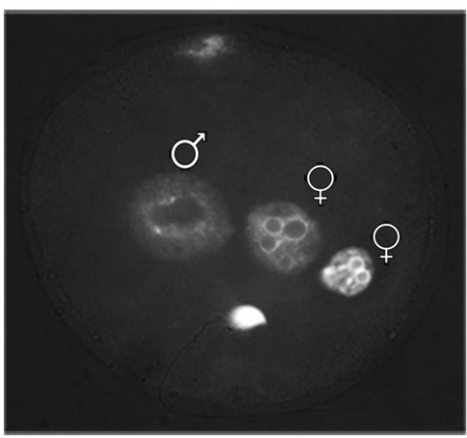

Fig. 3. DAPI staining of pronuclei at six hours after sperm insemination. Representative images of unfertilized (1PN), monospermic (2PNs) and plurispermic (3PNs) oocytes. Male pronuclei display a larger size in diameter. Bar, $10 \mu \mathrm{m}$.

\section{Discussion}

The classification of GV oocytes based on the analysis of chromatin organization identifies those that are developmentally incompetent and always arrest at the 2-cell stage (NSN), from those that own a developmental potential (SN), the latter comprising gametes that will complete preimplantation and others that will stop at earlier stages (Zuccotti et al., 1995; 1998; 2002; Inoue et al., 2008). In the present study, the analysis of chromatin organization of mouse GV oocytes was combined with the timing of occurrence of two key events during the first meiotic division. Time-lapse observation of the GV-to-MII transition brought up differences in the timing of GVBD and PB-I extrusion of SN and NSN oocytes. The analysis of these differences with unsupervised hierarchical clustering showed that the timing of GVBD was not a relevant parameter of oocytes classification; instead, it highlighted the presence of three main groups of gametes significantly different for their timing of PB-I extrusion: Group A, the most representative, comprised mainly SN oocytes (PB-I extrusion during 456-576 min interval), group B entailed an almost equivalent percentage of SN or NSN oocytes (584-728 min), and group $\mathrm{C}$, the smallest of the three groups, consisted of almost all NSN oocytes (736-896 min).

These results highlight the presence of two significantly distinguished subgroups of SN oocytes, one that completes MI earlier (Group A) than the other (Group B). To evaluate the developmental competence of these gametes, unclassified GV oocytes were in vitro matured and, depending on the timing of PB-I extrusion,

TABLE 2

\section{FREQUENCY OF UNFERTILIZED, MONOSPERMIC AND PLURISPERMIC OOCYTES}

\begin{tabular}{lcccc} 
& \multicolumn{4}{c}{ Mean \% \pm S.D. of fertilized oocytes } \\
\cline { 2 - 5 } & GROUP A & GROUP B & GROUP C & OVULATED \\
\cline { 2 - 5 } $\begin{array}{l}\text { Number of oocytes } \\
\text { inseminated }\end{array}$ & 44 & 57 & 16 & 97 \\
1 pronucleus & $11.2 \pm 13.6$ & $18.7 \pm 9.4$ & $14.8 \pm 17.0$ & $6.3 \pm 3.4$ \\
2 pronuclei & $80.2 \pm 12.2$ & $73.7 \pm 4.0$ & $73.1 \pm 5.8$ & $88.5 \pm 5.2$ \\
3 pronuclei & $11.4 \pm 10.8$ & $5.6 \pm 7.3$ & $15.7 \pm 13.7$ & $5.2 \pm 2.0$ \\
\hline
\end{tabular}

Oocytes were recorded six hours after sperm insemination of group A, B, C or control ovulated oocytes, which were compared using the ANOVA test ( $p>0.05$ in all the comparisons). sorted into group $\mathrm{A}, \mathrm{B}$ or $\mathrm{C}$. Following sperm insemination, the number of unfertilized, monospermic or pluripermic oocytes was similar not only for the three groups, but also when compared to in vivo matured and ovulated MII oocytes, an indication of the good quality of the zona pellucida (the limited number of unfertilized oocytes indicates that the zona pellucida did not undergo hardening) and of the IVM procedure as a whole. Whilst groups $B$ and $C$ showed a scarce or absent, respectively, development to blastocyst, group A oocytes completed preimplantation with a frequency of $26.2 \%$, similar to that $(28.9 \%)$ obtained with oocytes matured within intact COCs (Ge et al., 2008). These results indicate that among the $\mathrm{SN}$ class of oocytes, those that extrude the PB-I after the time-window of 456-576 min are developmentally incompetent and never reach the morula (Group $C$ ) or, with the exception of two embryos, the blastocyst (Group B) stage. Beside displaying a delayed $\mathrm{Ml}$ completion, these oocytes showed also perturbations of the GV-to-MII transition process and, more specifically, of the required unequal cytokinesis (Yi et al., 2013; Almonacid et al., 2018), evidenced by the presence of PB-Is significantly larger in size compared to those of Group A or control ovulated oocytes.

Up to date, two main alternatives to the use of the Hoechst fluorochrome have been proposed as non-invasive methods of GV oocyte classification: cumulus cells-specific transcript markers and ooplasmic movements occurring during the GV-to-MII transition. The whole-transcriptome analysis of the cumulus cells surrounding SN or NSN antral oocytes prior to their maturation to $\mathrm{MII}$, revealed 422 differentially expressed genes, 412 downregulated and 10 up-regulated in cumulus cells isolated from NSN oocytes compared to those from SN oocytes (Vigone et al., 2013). Among these transcripts, Amh (Anti-Müllerian hormone) and Has2 (Hyaluronan synthase 2) were those most differentially expressed with a 4-fold higher and 2-fold lower number of transcripts, respectively; and thus were suggested as putative molecular markers. In a further attempt to find non-invasive markers useful for GV oocytes classification, the cytoplasmic movements occurring during the GV-to-MII transition of SN and NSN oocytes were recorded and analyzed combining particle image velocymetry (PIV) with a trained artificial neural network (Bui et al., 2017), demonstrating the possible exploitation of these cytological changes as a signatures for the non-invasive assessment of the oocyte developmental potential. 
DAPI
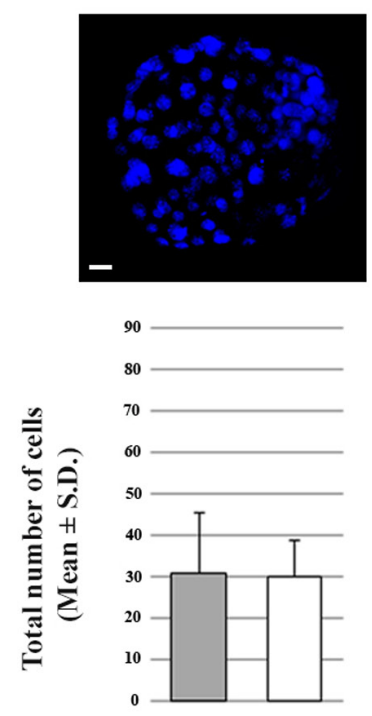

CDX2
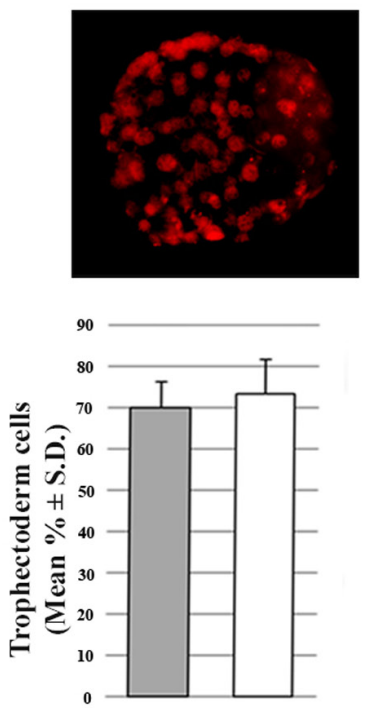

OCT4
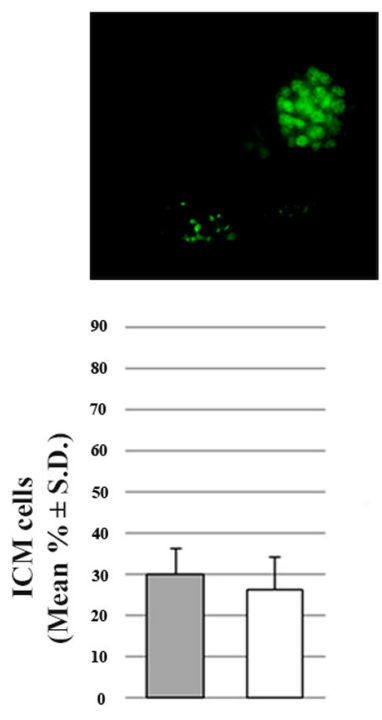

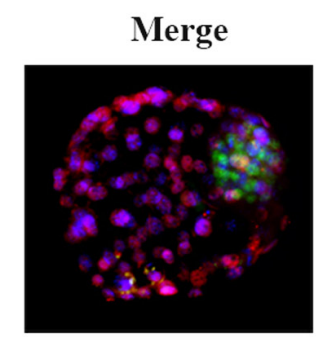

GROUPA

OVULATED MII

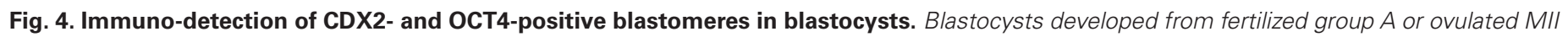

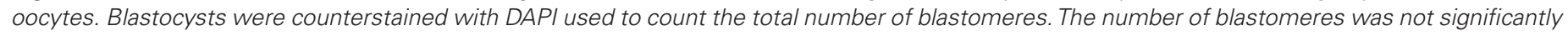
different (p>0.05) among the two groups analyzed. Bar, $10 \mu \mathrm{m}$.

The significant advance of the study presented here is that it shows a simple non-invasive method of selecting developmentally competent/incompetent SN/NSN oocytes based on the observation and recording of the timing of PB-I extrusion. Oocytes that display a shorter timing of PB-I extrusion and a small PB-I size (Group A) own a better developmental potential. On the contrary, those that display a longer timing of PB-I extrusion and a larger PB-I size (groups B and C) are of low quality.

The possibility to avoid the use of the invasive DNA-binding fluorochrome Hoechst opens for future applications in domestic animals and humans reproductive technologies.

\section{Materials and Methods}

\section{Animals and reagents}

Six-eight week-old females and 3-4 month-old males CD1 mice (Charles River, CO, Italy) were used for this study. Animals were housed under standard conditions of $21^{\circ} \mathrm{C}, 60 \%$ air humidity and a light cycle of $12 \mathrm{hr}$ dark and $12 \mathrm{hr}$ light and fed ad libitum. Mice manipulation was made with permission (n. 1100/2016-PR) and in agreement with the guiding principles of European (n. 2010/63/UE) and Italian (n. 26/2014) legislations. Except when indicated, all reagents were purchased from Sigma-Aldrich.

\section{Hormonal treatment}

For the isolation of fully-grown GV antral oocytes, females were intraperitoneally injected with 3.5 IU Folligon (Intervet Srl, Italy) and sacrificed $48 \mathrm{hr}$ later. To obtain ovulated MII oocytes, females were injected with 3.5 IU Folligon, followed by, $48 \mathrm{hr}$ later, an injection of 3.5 IU Chorulon (Intervet) and sacrificed after $15 \mathrm{hr}$.

\section{Isolation of fully-grown antral or ovulated metaphasell oocytes}

After ovaries insolation, the ovarian surface was punctured with a sterile 26G needle in M2 medium (Fulton and Whittingham, 1978) and fully-grown antral follicles, with an intact cumulus (Cumulus Oocyte Complexes, COCs) were collected using a hand-pulled sterile Pasteur pipette (Cavalera et al., 2018). In some experiments, intact COCs were matured in vitro and the fertilized (see below); in others, oocytes were freed from their surrounding cumulus cells by gently pipetting in and out with a mouth-controlled hand-pulled glass Pasteur micropipette. Ovulated MII oocytes were isolated from the oviducts of superovulated females in M2 medium supplemented with $500 \mathrm{IU} / \mathrm{ml}$ hyaluronidase type II to remove CCs.

\section{Oocyte classification based on chromatin organization}

Oocytes were singularly transferred into $5 \mu \mathrm{l}$ droplets of M2 medium containing the supravital fluorochrome Hoechst $33342(0.05 \mu \mathrm{g} / \mathrm{ml})$ and incubated for $15 \mathrm{~min}$ at room temperature (RT) in the dark. Then, after a brief wash in $\alpha$-MEM W/GLUTAMAX-I medium (Life Technologies) (supplemented with 5\% FBS, $25.3 \mathrm{mg} / \mathrm{ml}$ Sodium Pyruvate, $100 \mathrm{IU} /$ $\mathrm{ml}$ Penicillin, $75 \mu \mathrm{g} / \mathrm{ml}$ Streptomycin and $1 \mathrm{mg} / \mathrm{ml}$ Fetuin) oocytes were transferred in $\alpha$-MEM ( $2 \mu \mathrm{l} /$ oocyte) in a 3.5 -cm glass-bottom dish (WillCo Wells B.V., Amsterdam, the Netherlands), covered with mineral oil and placed in the incubation chamber $\left(37^{\circ} \mathrm{C}, 5 \% \mathrm{CO}_{2}\right)$ of a BioStation IM (Nikon) where they were first classified as SN or NSN under 2 seconds UV light exposure (Belli et al., 2014) and then matured in $\alpha$-MEM W/ GLUTAMAX-I medium (Life Technologies) (supplemented with $5 \%$ FBS, $25.3 \mathrm{mg} / \mathrm{ml}$ Sodium Pyruvate, $100 \mathrm{lU} / \mathrm{ml}$ Penicillin, 75 $\mu \mathrm{g} / \mathrm{ml}$ Streptomycin and $1 \mathrm{mg} / \mathrm{ml}$ Fetuin) for $15 \mathrm{hr}$, as described hereafter.

\section{Time-Lapse in vitro maturation of antral germinal vesicle oocytes to metaphasell}

Time-lapse images of maturing oocytes were taken at 8 min timeintervals for a total of $15 \mathrm{hr}$ with a 20X objective, under bright field light (intensity set at 39 , exposure time $1 / 20$ of a second, and gain 1.41). At the end of the culture period, the time-lapse movie obtained for each oocyte was re-winded and analyzed to assess both the timing of PB-I extrusion and GVBD. Also, the PB-I area of those GV oocytes that reached MII was measured using the CellSens software (Olympus).

\section{In vitro fertilization and preimplantation development}

About 90 min before the end of the COCs or oocytes maturation period, cauda epididymes were punctured with a sterile 26G needle, covered with $1.5 \mathrm{ml}$ Whittingham medium (Whittingham, 1971) and incubated for 
$20 \mathrm{~min}$ at $37^{\circ} \mathrm{C}$ and $5 \% \mathrm{CO}_{2}$. The top $300 \mu \mathrm{L}$ fraction of the medium was placed at the bottom of a $3.5 \mathrm{~cm}$ petri-dish (Corning) covered with mineral oil and incubated for $1 \mathrm{hr}$ at $37^{\circ} \mathrm{C}, 5 \% \mathrm{CO}_{2}$. Then, at completion of their 15 hr maturation MII oocytes were transferred into $100 \mu \mathrm{l}$ drop of capacitated sperm at the final concentration of $1.8 \times 10^{6} / \mathrm{ml}$ and incubated at $37^{\circ} \mathrm{C}, 5 \%$ $\mathrm{CO}_{2}$ for $2 \mathrm{hr}$. Control ovulated MII oocytes were inseminated in parallel. Presumptive zygotes were washed into a series of $40 \mu \mathrm{L}$ drops of pre-warmed M16 medium to remove excess of sperm and incubated in M16 drops ( $2 \mu \mathrm{l} /$ oocyte) to allow preimplantation development.

\section{Analysis of pronuclei formation}

Six hours after insemination, oocytes were fixed in paraformaldehyde (4\% PFA in 1X PBS), stained with DAPI $(0.2 \mu \mathrm{g} / \mathrm{ml}$ in $1 X$ PBS) for $15 \mathrm{~min}$ and observed under an Olympus BX60 epifluorescence microscope.

\section{Immunofluorescence}

Blastocysts obtained from in vitro matured oocytes together with those obtained by fertilization of ovulated MIl oocytes were analyzed by immunofluorescence for the presence of OCT4 and CDX2 protein markers of the blastocyst ICM and TE, respectively. Cells were fixed into $40 \mu \mathrm{L}$ droplets of Paraformaldehyde (4\% PFA in 1X PBS) for 20 min. After fixation, cells were permeabilised with $0.5 \%$ Triton X100 in 1 X PBS for 20 min at RT and incubated in the wash solution (WS) [100 mg Powered Milk, $100 \mathrm{mg}$ BSA, 20 mg Glycine, $50 \mu \mathrm{L}$ Tween 20, $200 \mu \mathrm{L}$ FBS] for 20 min at RT. Embryos were then processed for sequential immunolabeling using a rabbit polyclonal anti-human OCT4 (Abcam, cat. n. ab19857) and a rabbit anti-human CDX2 (Cell Signaling, cat. n 3977S) antibody. Briefly, cells were incubated with antiOCT4 primary antibody (diluted 1:100 in 1 X PBS) for $1 \mathrm{hr}$ at $37^{\circ} \mathrm{C}$, washed three times in gentle agitation with WS for 25 min each, and incubated $1 \mathrm{hr}$ at $37^{\circ} \mathrm{C}$ with the secondary Alexa Fluor 488 conjugated goat anti-rabbit lgG antibody (1:1000 diluted in 1XPBS, Molecular Probes). Following, blastocysts were incubated overnight at $4^{\circ} \mathrm{C}$ with anti-CDX2 primary antibody (diluted 1:50 in 1XPBS), washed three times with WS for 25 min each, and incubated with Alexa Fluor 555 conjugated anti-rabbit IgG antibody (1:750 diluted in 1X PBS, Molecular Probes) for $1 \mathrm{hr}$ at $37^{\circ} \mathrm{C}$. After immunostaining, embryos washed three times for 25 min each in WS and counterstained with DAPI $(0.2 \mu \mathrm{g} / \mathrm{ml}$ in $1 \mathrm{X}$ PBS for $10 \mathrm{~min}$ at RT). Slides were mounted in Vectashield (Vector Lab, Italy) and observed under an Olympus BX60 epifluorescence microscope equipped with a Tango motorised Z-axis (Märzhäuser Wetzlar, Wetzlar, Germany) and single-bandpass filters for DAPI, Alexa 555 and 488. Images were acquired using an Olympus DP72 digital camera controlled by Olympus CellSens Dimension 1.4.1 software.

\section{Statistical analysis}

Statistical analyses were carried out using the Sigma Stat 3.0 software. Normally distributed data were analyzed by the Student's t-test for comparing two conditions or by the one-way ANOVA for comparing more than two groups. One-way ANOVA test was followed by the Fisher LSD Method (post-hoc test) when significant differences were present. When data were not normally distributed, statistical analysis was performed either by the Mann-Whitney test (when the comparison involved two samples) or by the Kruskal-Wallis test together with the Dunn's multiple range test (for the comparison of more than two samples). Parametric and nonparametric data are expressed as the mean \pm standard deviation (SD). The analysis of the absolute frequencies was performed using a Fisher's exact test. Timing of GVBD and PB-I extrusion were analyzed using unsupervised hierarchical clustering with Euclidean distance (Hastie et al., 2001). Differences were considered significant for $p$ values $\leq 0.05$.

\section{Acknowledgements}

This work was made possible thanks to support by: the Italian Ministry of Education, University and Research (MIUR): Dipartimenti di Eccellenza Program (2018-2022) - Dept. of Biology and Biotechnology "L. Spallanzani", University of Pavia; University of Pavia FRG 2017; Merck-Lab water; and Kinesis for supplying the plasticware necessary to carry out this study.

\section{References}

ALMONACID M., TERRET M.E., VERLHAC M.H. Control of nucleus positioning in mouse oocytes. (2018) Semin. Cell. Dev. Biol. 82: 34-40.

BELLI, M., VIGONE, G., MERICO, V., REDI, C. A., GARAGNA, S., ZUCCOTTI, M. (2014). Time-lapse dynamics of the mouse oocyte chromatin organisation during meiotic resumption. Biomed. Res. Int. 207357. DOI: 10.1155/2014/207357.

BOUNIOL-BALY, C., HAMRAOUI, L., GUIBERT, J., BEAUJEAN, N., SZOLLOSI, M., DEBEY, P. (1999). Differential transcriptional activity associated with chromatin configuration in fully grown mouse germinal vesicle oocytes. Biol. Reprod. 60: 580-587.

BUIT.T., BELLI, M., FASSINAL., VIGONE G., MERICO V., GARAGNAS., ZUCCOTTI, M. (2017). Cytoplasmic movement profiles of mouse surrounding nucleolus and not-surrounding nucleolus antral oocytes during meiotic resumption. Mol. Reprod. Dev. 9999: 1-7

CAN, A., SEMIZ, O., CINAR, O. (2003). Centrosome and microtubule dynamics during early stages of meiosis in mouse oocytes. Mol. Hum. Reprod. 9: 749-756.

CAVALERA, F., ZANONI, M., MERICO, V., BUI, T.T.H., BELLI, M., FASSINA, L., GARAGNA, S., ZUCCOTTI, M. (2018). A Neural Network-Based Identification of Developmentally Competent or Incompetent Mouse Fully-Grown Oocytes. J. Vis. Exp. 133. doi: $10.3791 / 56668$.

DEBEY, P., SZÖLLÖSI, M.S., SZÖLLÖSI, D., VAUTIER, D., GIROUSSE, A. AND BESOMBES, D. (1993). Competent mouse oocytes isolated from antral follicles exhibit different chromatin organization and follow different maturation dynamics. Mol. Reprod. Dev. 36: 59-74.

FULTON, B.P. AND WHITTINGHAM, D.G. (1978). Activation of mammalian oocytes by intracellular injection of calcium. Nature. 273: 149-151.

GE, L., HAN, D., LAN, G.C., ZHOU, P., LIU, Y., ZHANG, X., SUI, H.S. AND TAN, J.H. (2008). Factors affecting the in vitro action of cumulus cells on the maturing mouse oocytes. Mol. Reprod. Dev. 75: 136-142.

HASTIE, T., TIBSHIRANI, R., FRIEDMAN, J. (2001). Hierarchical clustering in The Elements of Statistical Learning New York, Springer, pp. 272-280, ISBN 0-387-95284-5.

INOUE, A., NAKAJIMA, R., NAGATA, M. AND AOKI, F. (2008). Contribution of the oocyte nucleus and cytoplasm to the determination of meiotic and developmental competence in mice. Hum. Reprod. 23: 1377-1384.

KAGEYAMA, S., LIU, H., KANEKO, N., OOGA, M., NAGATA, M. AND AOKI, F. (2007). Alterations in epigenetic modifications during oocyte growth in mice. Reprod. 133: 85-94.

MALLOLA., SANTALÓJ., IBÁÑEZE. Comparison of three differential mouse blastocyst staining methods. (2013). Syst. Biol. Reprod. Med. 59:117-122.

NAVARRO, P.A., DE ARAÚJO, M.M., DE ARAÚJO, C.M., ROCHA, M., DOS REIS, R. AND MARTINS, W. (2009). Relationship between first polar body morphology before intracytoplasmic sperm injection and fertilization rate cleavage rate and embryo quality. Int. J. Gynecol. Obstet. 104: 226-229.

RIENZI, L., UBALDI, F.M., IACOBELLI, M., MINASI, M.G., ROMANO, S., FERRERO, S., SAPIENZA, F., BARONI, E., LITWICKA, K. AND GRECO, E. (2008). Significance of metaphase II human oocyte morphology on ICSI outcome. Fertil. Steril. 90: 1692-1700.

TAN, J.H., WANG, H.L., SUN, X.S., LIU, Y., SUI, H.S. AND ZHANG, J. (2009). Chromatin configurations in the germinal vesicle of mammalian oocytes. Mol. Hum. Reprod. 15: 1-9.

VAN THUAN, N., WAKAYAMA, S., KISHIGAMI, S., OHTA, H., HIKICHI, T., MIZUTANI, E., BUI, H.T., WAKAYAMA, T. (2006). Injection of somatic cell cytoplasm into oocytes before intracytoplasmic sperm injection impairs full term development and increases placental weight in mice. Biol. Reprod. 74: 865-873.

VIGONE, G., MERICO, V., PRIGIONE, A., MULAS, F., SACCHI, L., GABETTA, M., BELLAZZI, R., REDI, C.A., MAZZINI, G., ADJAYE, J., GARAGNA, S. AND ZUCCOTTI, M. (2013). Transcriptome based identification of mouse cumulus cell markers that predict the developmental competence of their enclosed antral oocytes. BMC Genomics. 14: 380.

WHITTINGHAM, D.G. (1971). Culture of mouse ova. J. Reprod. Fertil. Suppl. 14:7-21.

WICKRAMASINGHE, D., ALBERTINI, D.F. (1992). Centrosome phosphorylation and the developmental expression of meiotic competence in mouse oocytes. Dev. Biol. 152: 62-74.

YI K., RUBINSTEIN B., LI R. Symmetry breaking and polarity establishment dur- 
ing mouse oocyte maturation. (2013) Philos Trans R Soc Lond B Biol Sci. 368: 20130002.

ZUCCOTTI, M., GARAGNA, S., MERICO, V., MONTI, M. AND REDI, C.A. (2005). Chromatin organisation and nuclear architecture in growing mouse oocytes. Mol. Cell. Endocrinol. 234: 11-17.

ZUCCOTTI, M., GIORGI ROSSI, P., MARTINEZ, A., GARAGNA, S., FORABOSCO, A. AND REDI C.A. (1998). Meiotic and developmental competence of mouse antral oocytes. Biol. Reprod. 58: 700-704.

ZUCCOTTI, M., MERICO, V., BELLI, M., MULAS, F., SACCHI, L., ZUPAN, B., REDI, C.A., PRIGIONE, A., ADJAYE, J., BELLAZZI, R. AND GARAGNA, S. (2012). OCT4 and the acquisition of oocyte developmental competence during folliculogenesis Int. J. Dev. Biol. 56: 853-858.

ZUCCOTTI, M., MERICO, V., BELLONE, M., MULAS, F., SACCHI, L., REBUZZINI, P., PRIGIONE, A., REDI, C.A., BELLAZZI, R., ADJAYE, J. AND GARAGNA, S. (2011). Gatekeeper of pluripotency: a common Oct4 transcriptional network operates in mouse eggs and embryonic stem cells. BMC Genomics. 12: 1-13.
ZUCCOTTI, M., MERICO, V., SACCHI, L., BELLONE, M., BRINK, T., STEFANELLI, M., REDI, C., BELLAZZI, R., ADJAYE, J., GARAGNA, S. (2009). Oct-4 regulates the expression of Stella and Foxj2 at the Nanog locus: implications for the developmental competence of mouse oocytes. Hum. Reprod. 9: 2225-2237.

ZUCCOTTI, M., MERICO, V., SACCHI, L., BELLONE, M., BRINK, T.C., BELLAZZI R., STEFANELLI, M., REDI, C., GARAGNA, S. AND ADJAYE, J. (2008). Maternal Oct-4 is a potential key regulator of the developmental competence of mouse oocytes. BMC Dev. Biol. 8: 97

ZUCCOTTI, M., PICCINELLI, A., GIORGI ROSSI, P., GARAGNA, S. AND REDI, C.A. (1995). Chromatin organization during mouse oocyte growth. Mol. Reprod. Dev. 41: 479-485.

ZUCCOTTI, M., PONCE, R.H., BOIANI, M., GUIZZARDI, S., GOVONI, P., SCANDROGLIO, R., GARAGNA, S. AND REDI, C.A. (2002). The analysis of chromatin organisation allows selection of mouse antral oocytes competent for development to blastocyst. Zygote. 10: 73-78. 


\section{Further Related Reading, published previously in the Int. J. Dev. Biol.}

The NOBOX protein becomes undetectable in developmentally competent antral and ovulated oocytes.

Martina Belli, Danilo Cimadomo, Valeria Merico, Carlo Alberto Redi, Silvia Garagna and Maurizio Zuccotti

Int J Dev Biol. (2013) 57: 35-39

https://doi.org/10.1387/ijdb.120125mz

Histone hyperacetylation during meiosis interferes with large-scale chromatin remodeling, axial chromatid condensation and sister chromatid separation in the mammalian oocyte

Feikun Yang, Claudia Baumann, Maria M. Viveiros and Rabindranath De La Fuente

Int. J. Dev. Biol. (2012) 56: 889-899

https://doi.org/10.1387/ijdb.120246rd

Genome organization and epigenetic marks in mouse germinal vesicle oocytes Amelie Bonnet-Garnier, Prisca Feuerstein, Martine Chebrout, Renaud Fleurot, Habib-Ullah Jan, Pascale Debey and Nathalie Beaujean

Int. J. Dev. Biol. (2012) 56: 877-887

https://doi.org/10.1387/ijdb.120149ab

Knowledge-based bioinformatics for the study of mammalian oocytes.

Francesca Mulas, Lucia Sacchi, Lan Zagar, Silvia Garagna, Maurizio Zuccotti, Blaz Zupan and Riccardo Bellazzi

Int. J. Dev. Biol. (2012) 56: 10-12

https://doi.org/10.1387/ijdb.120138fm

Chromatin dynamics of the developmentally regulated $P$. lividus neural alpha tubulin gene Marco Emanuele, Salvatore Costa, Maria Antonietta Ragusa and Fabrizio Gianguzza Int. J. Dev. Biol. (2011) 55: 591-596

https://doi.org/10.1387/ijdb.103264me
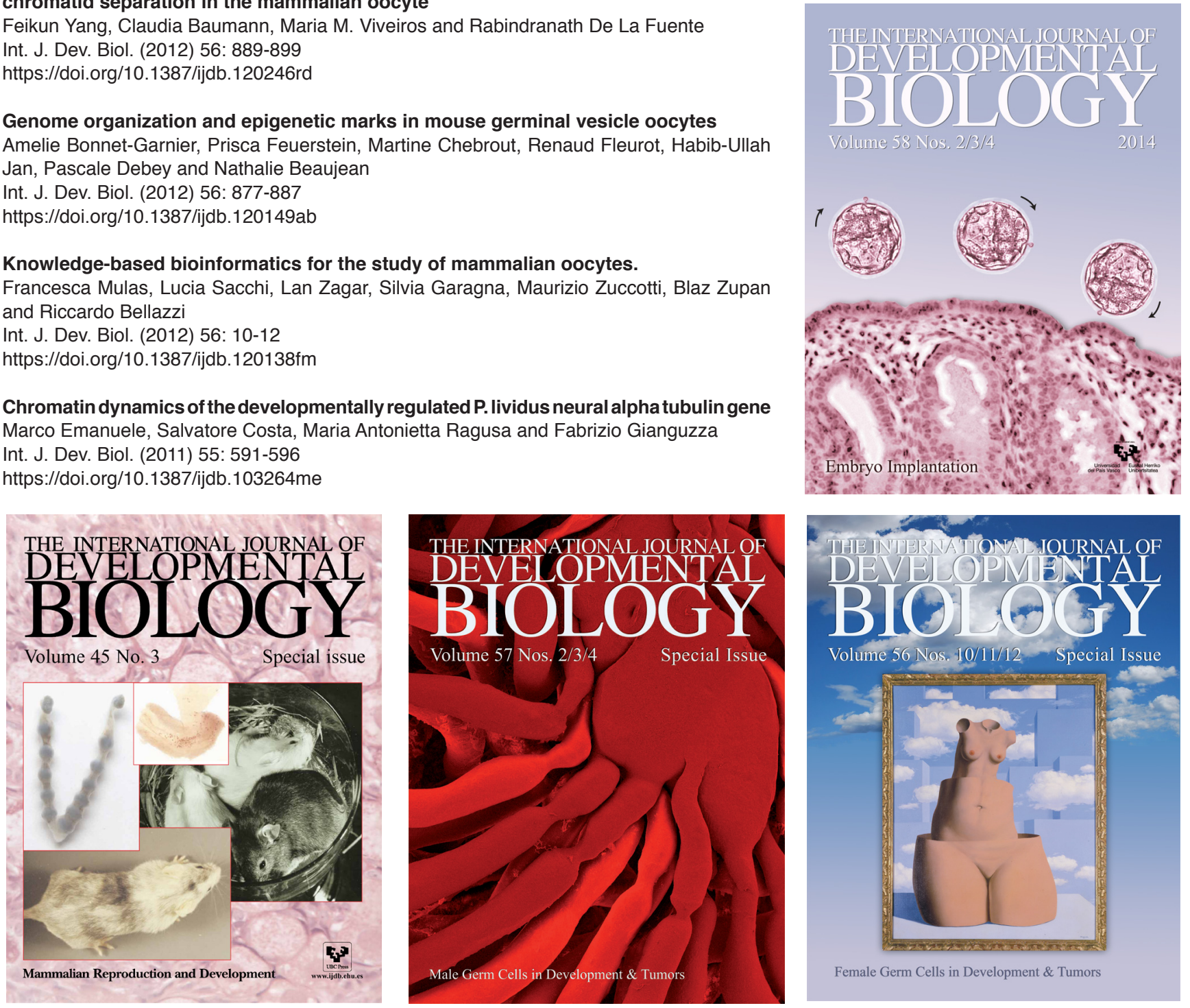